\title{
Long melt seasons on ice shelves of the Antarctic Peninsula: an analysis using satellite-based microwave emission measurements
}

\author{
Mark A. Fahnestock, ${ }^{1}$ Waleed Abdalati, ${ }^{2}$ Christopher A. Shuman ${ }^{1}$ \\ ${ }^{1}$ Earth System Studies Interdisciplinary Center, University of Maryland, College Park, MD 20742-2465, U.S.A. \\ ${ }^{2}$ NASA Headquarters, Washington, DC 20546-0001, U.S.A.
}

\begin{abstract}
We have examined the record of melt-season duration on the Antarctic Peninsula using two techniques for detecting the presence of a melt signal in microwaveemission time series covering the period 1978-2000. We have obtained similar estimates of melt-season length using the cross-polarized gradient ratio (XPGR) technique and calibrations previously applied in Greenland and a technique which detects the jump in emission caused by melt without using a sensor- and frequency-dependent threshold value. The close correspondence between results from the two techniques on peninsula ice shelves suggests that the XPGR analysis can be used over the length of the time series. The results show that the long melt seasons of 1992/93 and several later years were exceptional occurrences on the northern parts of the Larsen Ice Shelf. These melt seasons were followed by disintegration events, supporting a possible cause-and-effect relationship.
\end{abstract}

\section{INTRODUGTION}

Several processes drive variations in microwave emission from firn on the large ice sheets. Temperature variations in the firn produce changes in emission by changing the amount of energy emitted in the source region, while changing firn conditions such as recrystallization and changes in surface conditions (hoar frost, layering or crusts produced by wind or radiation) change the amount of scattering experienced by the radiation on the way to the surface of the snow (see, e.g., Ulaby and others, 1981; Shuman and Alley, 1993; Abdalati and Steffen, 1998). These short- and long-term variations occur in all firn on the ice sheet and are responsible for the variability we observe in areas where the surface does not melt.

In areas that melt, there is an additional process that changes the strength of the microwave emission from the surface of the snow. The presence of a small amount of liquid water produces a sharp increase in the amount of energy emitted (e.g. Zwally and Gloersen, 1977). Several investigators have used this change to map the extent and duration of melting on the large ice sheets. Abdalati and Steffen (1995) and Mote and Anderson (1995) mapped the extent and duration of melt on the Greenland ice sheet by exploiting different aspects of this increase in emissivity. In Antarctica, Ridley (1993) and Zwally and Fiegles (1994) produced records of the patterns and extent of melting in different areas. Ridley, looking at data spanning 1978-91, observed slowly increasing melt-season durations on a number of ice shelves on the Antarctic Peninsula. He used a threshold level for the microwave emission to determine melting. Zwally and Fiegles mapped the length of the melt season around the continent using locally determined threshold values that are based on a set increase above the long-term average at a site, using data spanning the period 1978-87.

Recent break-ups of ice shelves along the Antarctic
Peninsula (e.g. Vaughan, 1993; Rott and others, 1996, 1998; Doake and others, 1998; Lucchitta and Rosanova, 1998; Scambos and others, 2000) and evidence for warming (e.g. King, 1994; Vaughan and Doake, 1996; Skvarca and others, 1998) have suggested changing conditions in the area. In this paper we re-examine the question of surface melt on the Antarctic Peninsula to extend the time series of melt into the period when a number of rapid calving events have been documented in the area. Scambos and others (2000) argue that ponding of water on the surface of an ice shelf may provide the conditions required for an ice shelf to break up in place and later disintegrate due to a passing storm system. In their analysis, a time series of surface melt is used to show that melt ponding occurs during longer melt seasons in the 1990s.

\section{DATA AND ANALYSIS}

The time series of satellite-measured microwave emission, reported as brightness temperature $(\mathrm{Tb})$, from firn that we use in the present analysis covers measurements from the Scanning Multichannel Microwave Radiometer (SMMR) (1978-87) and three different satellites carrying Special Sensor Microwave/Imager (SSM/I) instruments. For a discussion of the relevant characteristics of these instruments, and the datasets they produced, see Abdalati and Steffen (1997) and references therein. There are differences between these datasets that can affect the measurement of meltseason length. We have used two techniques for measuring the spatial and temporal variations in melt-season length on the ice shelves of the peninsula. These techniques differ in their approach to detecting the changing emission due to melt. A comparison of the results from the techniques gives us more confidence that differences between sensors used to produce the time series of melt history do not bias the results. 


\section{XPGR}

Abdalati and Steffen (1997) used the changes in emission at $19 \mathrm{GHz}$ horizontal polarization $\left(\mathrm{Tb}_{19 \mathrm{H}}\right)$ and $37 \mathrm{GHz}$ vertical polarization $\left(\mathrm{Tb}_{37 \mathrm{~V}}\right)$, combined in a quantity they term the cross-polarized gradient ratio (XPGR), to indicate melt in Greenland.

$$
\mathrm{XPGR}=\frac{\mathrm{Tb}_{19 \mathrm{H}}-\mathrm{Tb}_{37 \mathrm{~V}}}{\mathrm{~Tb}_{19 \mathrm{H}}+\mathrm{Tb}_{37 \mathrm{~V}}} .
$$

Near-surface melt ( $\sim 1 \%$ water in the upper meter of firn) is assumed to be present in a pixel when this ratio exceeds a threshold value that has been set based on field observations and theoretical considerations. Differences between sensor characteristics, imaging geometries and over-flight times caused them to use a different threshold for the earliest dataset they considered, which came from the SMMR sensor. This change in threshold was required by the lower frequency (18 GHz instead of $19.25 \mathrm{GHz}$ for $\mathrm{SSM} / \mathrm{I}$ ) and because the satellite revisit times occurred at different times of day. We have used the same data-calibration techniques and thresholds they describe to produce maps of melt-season duration on the Antarctic Peninsula using XPGR. Our results for the period 1978-2000 are shown in Figure 1. The year indicated on each map is the year the melt season began (thus 94 represents melt during the 1994/95 austral summer). smmr78

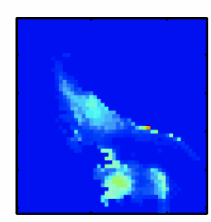

smmr83

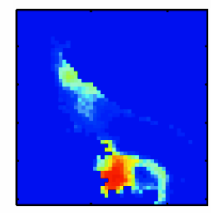

ssmi88

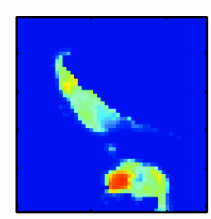

ssmi93

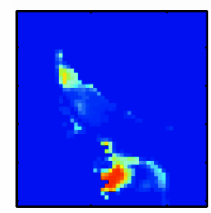

ssmi98

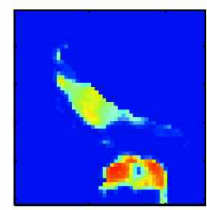

smmr79

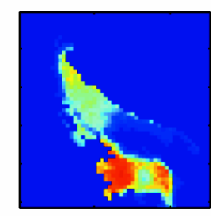

smmr84

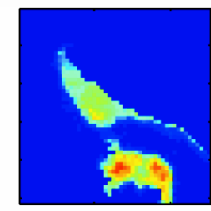

ssmi89

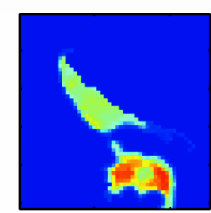

ssmi94

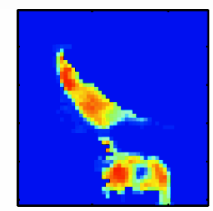

melt-season

ssmi99

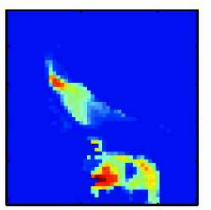

length (days) smmr80

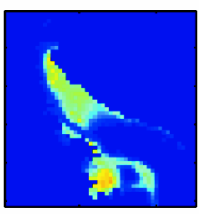

smmr85

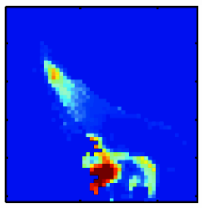

ssmi90

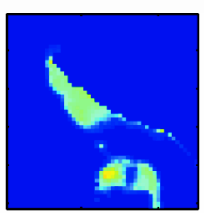

ssmig5

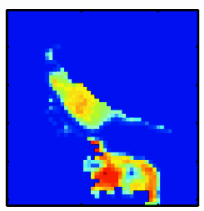

ssmi96

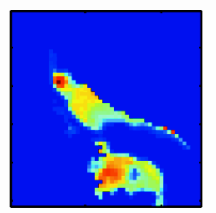

ssmi97
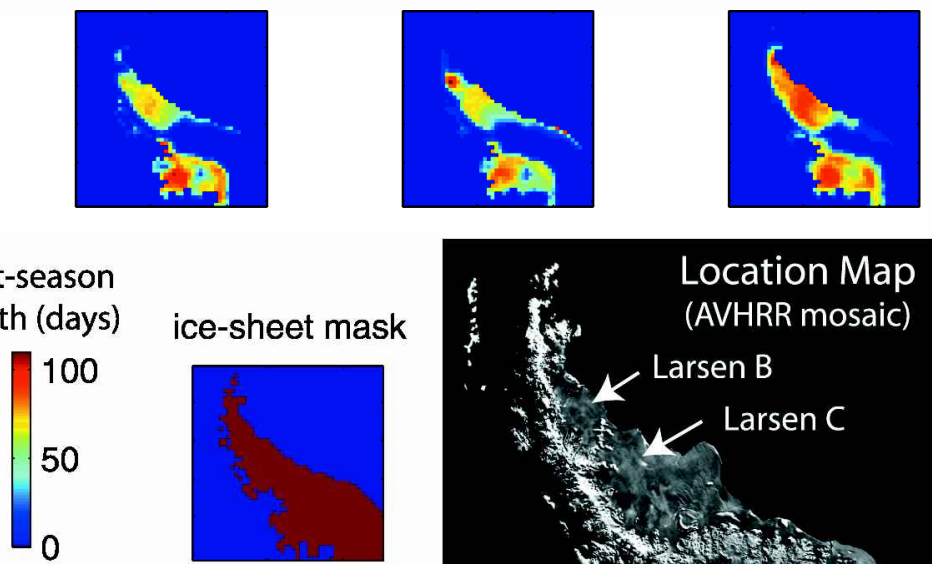

ice-sheet mask

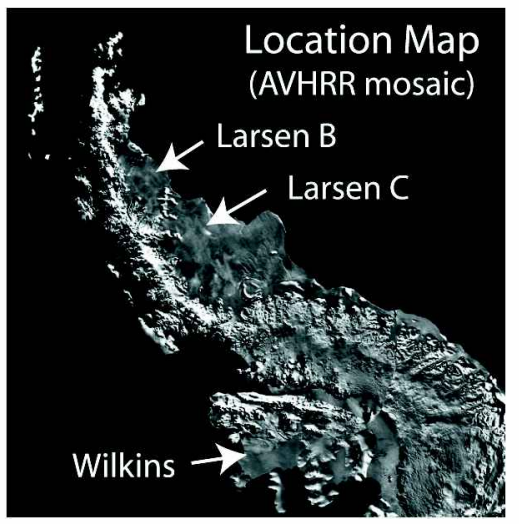

Fig. 1. Map of melt-season lengths on the Antartic Peninsula determined using the XPGR analysis of Abdalati and Steffen (1997). The sensor used for the period and the year in which each melt season began are labeled on the maps. The location map is extracted from the U.S. Geological Survey AVHRR mosaic of Antarctica. 


\section{Bimodal histograms as an indication of melt}

As a check on the changes in threshold required by changes in sensors over the time series, we have investigated alternative methods for detecting melt signals in the passive-microwave data. Zwally and Fiegles (1994) looked at the melt signal on the peninsula by computing the total melt-pixeldays in a region, but they used thresholding techniques which varied from pixel to pixel (based on background averages) and did not map the spatial patterns of melt- season length on a year-by-year, pixel-by-pixel basis. In addition, their analysis stopped with data from 1987, which was just prior to a number of long melt seasons in the area.

As we are interested in the relationship between surface melt and ice-shelf break-up, we wish to map the spatial variation of melt-season length over the available microwave record in a manner which is consistent from sensor to sensor; this will allow a check on the results of the XPGR analysis in Antarctica. We present a method that does not rely on changing thresholds from location to location or from sensor to
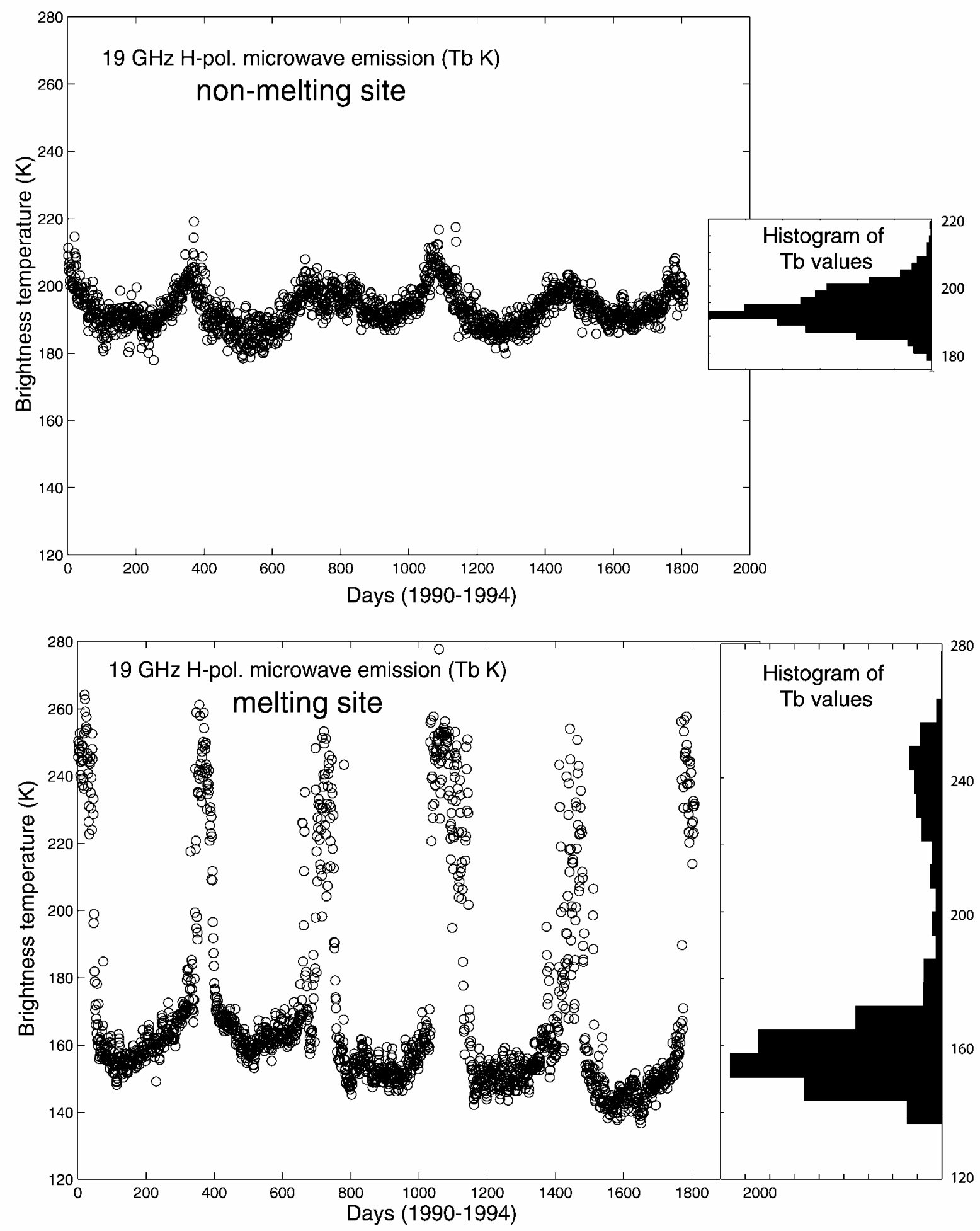

Fig. 2. Measured microwave emission (expressed as brightness temperature) for two pixels on the Antarctic Peninsula, 1 January 1990 to 31 December 1994. The frequency of occurrence of brightness-temperature values within each time series is shown by the histograms on the righthand side. The large jumps in emission in the summer in the lower plot are due to the change in emission caused by melt. Note the bimodal distribution in the histogram for the lower plot due to this jump in emission. 
sensor. The intent is to confirm the results from XPGR analysis without using the same assumptions about how melt affects the emission measured by different sensors.

The feature we exploit (in the same way in all emission records) to detect melting at a pixel is to look for the jump in emission related to the presence of water in the surface snow. While this jump may be detectable by a method using a threshold-based analysis, different thresholds are required for different sensors and different frequencies. We can avoid this difficulty if we use another criterion to detect the presence of a jump in an emission time series. This jump produces a bimodal distribution in a histogram of brightnesstemperature $(\mathrm{Tb})$ values over a year (see Fig. 2). This occurs because the $\mathrm{Tb}$ values when melt is present cluster around a value that is substantially higher than values from the rest of the year; the transition from non-melting to melting is rapid and the change in $\mathrm{Tb}$ is distinct, so there are few values of $\mathrm{Tb}$ which would lie in the transition region. It is clear to one's eye that the histogram of $\mathrm{Tb}$ values from a non-melting pixel is unimodal, while the histogram from a melting pixel is bimodal; it is more difficult to have an automated system recognize this difference. We accomplish this recognition by sorting the daily $\mathrm{Tb}$ values for a season by increasing magnitude, producing a curve with the lowest $\mathrm{Tb}$ values on the left which gradually increases to higher emission values on the right (Fig. 3). If the pixel experiences melt,
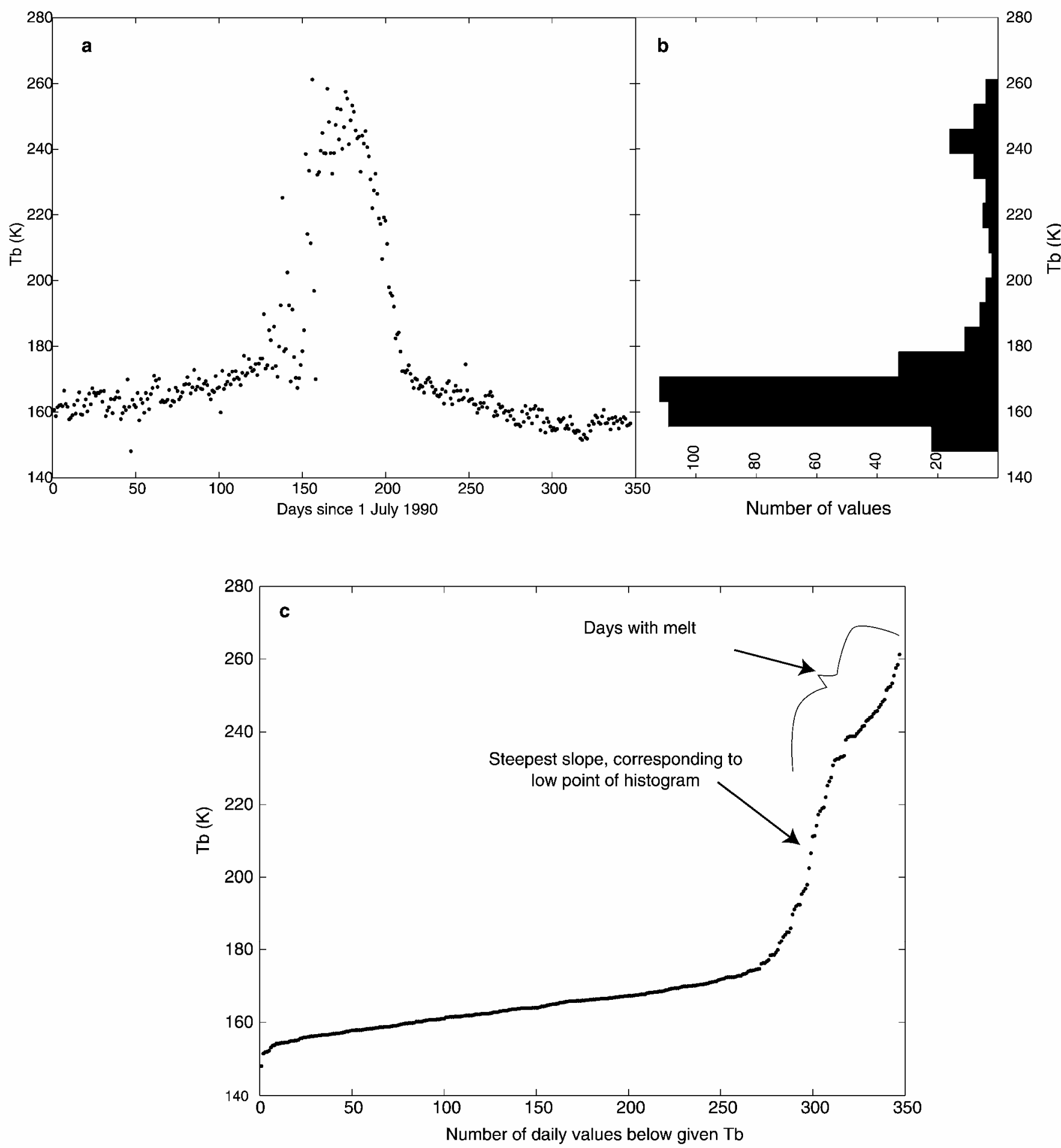

Fig. 3. (a) Time series of $19 \mathrm{GHz}$ Hemission from pixel located on Larsen B Ice Shelf. (b) Histogram of the data in (a). (c) The data from (a) sorted into ascending $\mathrm{Tb}$ order, with the high-slope point indicated. The pixels to the right of this high-slope point correspond to the pixels in the high-Tb cluster in the histogram; they are counted as days of melt as discussed in the text. 
there will be a steep section of this curve through the transition region. This section is steep because there are relatively few values in the transition region (this is the low point between the two modes in the bimodal distribution of $\mathrm{Tb}$ values through the year). We can detect this low point by looking for the maximum slope in the curve in Figure 3. All points with $\mathrm{Tb}$ values above the steepest gradient (to the right) are then counted as melting days; if the distribution is not bimodal, the steepest section will come at the right side (high-value end) of the curve, indicating that the surface did not melt for a substantial period. Because of difficulties in recognizing a steep slope due to melting if there are only a few days of melt, we do not label a pixel as melting if the season is shorter than 10 days in this analysis.

This bimodal technique is based on recognizing the rapid transition or jump in emission as melting begins; it is not dependent on the calibration of any given sensor and so may be applied to each instrument involved in the creation of the time series of microwave emission in exactly the same way, with one exception. The data from the SMMR instrument, covering the period 1978-87, have a sampling frequency of once every 2 days because of other requirements that were placed on the satellite. Rather than interpolating this data to fill in the missing days, we have chosen to doublecount the days in the record (equivalent to a nearest-neighbor interpolation), as this prevents the creation of extra values which would fall in the transition region each time the signal went from melting to non-melting or back over a 2 day period. With this exception, we have treated the data from SMMR and each of the SSM/I instruments identically with our analysis. Figure 4 shows the spatial and temporal changes in melt-season length determined with this bimodal analysis on $18 \mathrm{GHz}(\mathrm{SMMR})$ and $19 \mathrm{GHz}(\mathrm{SSM} / \mathrm{I})$ horizontally polarized emission time series. smmr78

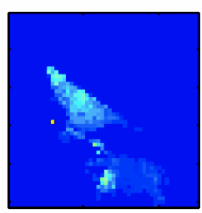

smmr83

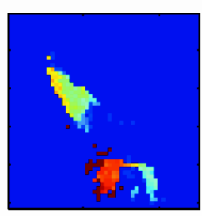

ssmi88

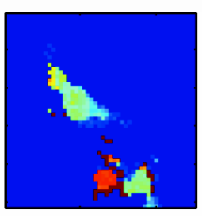

ssmi93

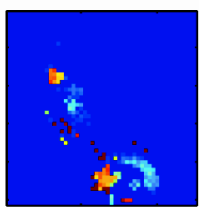

ssmi98

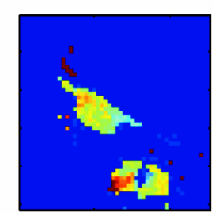

smmr79

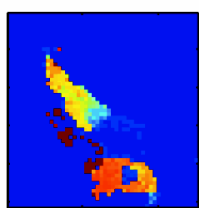

smmr84

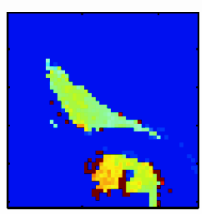

ssmi89

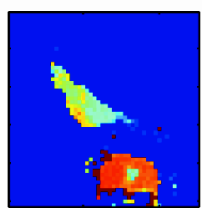

ssmi94

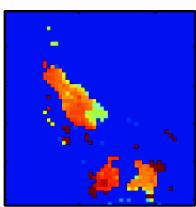

ssmi99

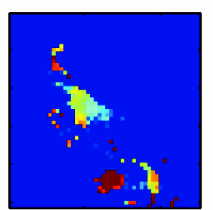

smmr80

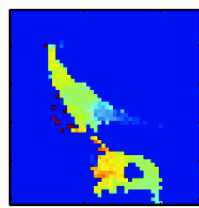

smmr85

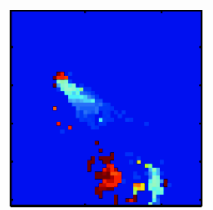

ssmi90

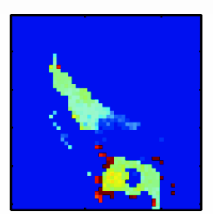

ssmi95

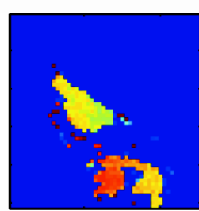

melt-season

length (days)

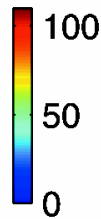

smmr82

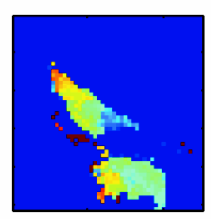

smmr86

Ssmi87
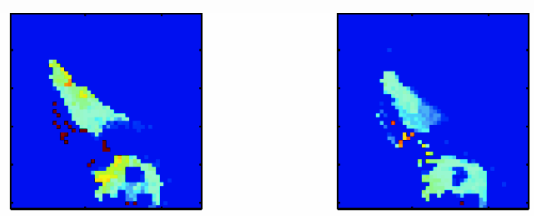

ssmi92
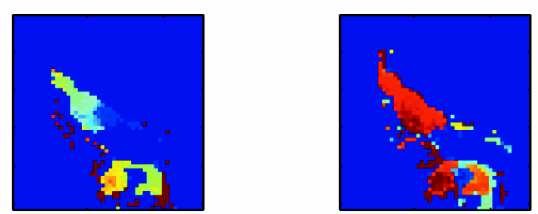

ssmi97
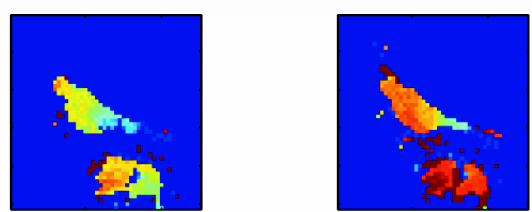

Fig. 4. Map of melt-season lengths on the Antarctic Peninsula determined using the bimodal analysis discussed in the text. The sensor used for the period, and the year in which each melt season began are labeled on the maps. 


\section{RESULTS AND DISGUSSION}

The patterns and length of melt season from the bimodal technique are quite similar to the results from the XPGR analysis, although the spatial patterns from the bimodal technique are clearly noisier (cf. Figs 1 and 4). The similarities are best illustrated by the comparisons for three different pixels on the Larsen and Wilkins Ice Shelves shown in Figure 5. For the Larsen B and Larsen $\mathrm{C}$ pixels the length of melt season is nearly independent of the technique used for the determination over the entire record. For the Wilkins pixel, XPGR shows shorter melt seasons during the 1990s than the bimodal technique. The close correspondence in melt-season length on the Larsen gives us some confidence in the record from XPGR in spite of changes in threshold values and calibrations between sensors; in this sense it confirms the work of Abdalati and Steffen (1997) in Greenland, and extends their work to the Antarctic Peninsula.

The XPGR record shows less spatial variability than the bimodal technique, and is preferable for looking at the localization of melting during long melt seasons. It is clear from the record for 1992/93 and other long melt seasons on the Larsen and Wilkins that localized extensive melting occurred near the locations of later disintegration events, as argued by Scambos and others (2000). The local enhancement of energy available for melting due to the lowered surface albedo in wet areas, especially in areas that have surface ponds, would cause small spatial variations in surface temperature and sensible-heat transfer to the surface to produce large variations in the amount of melting. This is a straightforward expression of an ice--albedo feedback localizing extensive melting, and may play an important role in the failure of an ice shelf.

The mechanism hypothesized to connect localized melting to the failure of an ice shelf is discussed by Scambos and others (2000). They show that long melt seasons correlate with the appearance of melt ponds on the surface, and hypothesize that ponded water filling crevasses allows the shelf to break up or weaken in place, making it susceptible to disintegration.

\section{GONGLUSIONS}

Our present analysis allows us to show how the length of melt seasons has varied spatially on an annual basis over the length of the satellite record. The similarity of the results from the SMMR period derived from the two methods suggests that the techniques of Abdalati and Steffen are effective over the whole record. In Antarctica this record shows that melt seasons on the Larsen Ice Shelf have been of exceptional length several times during the last decade. These seasons are shown by Scambos and others (2000) to have led to melt ponding, and so may be related to the failures of these areas that followed soon after. Longer-term monitoring of the remaining Antarctic ice shelves by this means may provide clearer documentation of the cause and effect suggested by Scambos and others (2000), as well as indications of which shelves may be susceptible to disintegration.
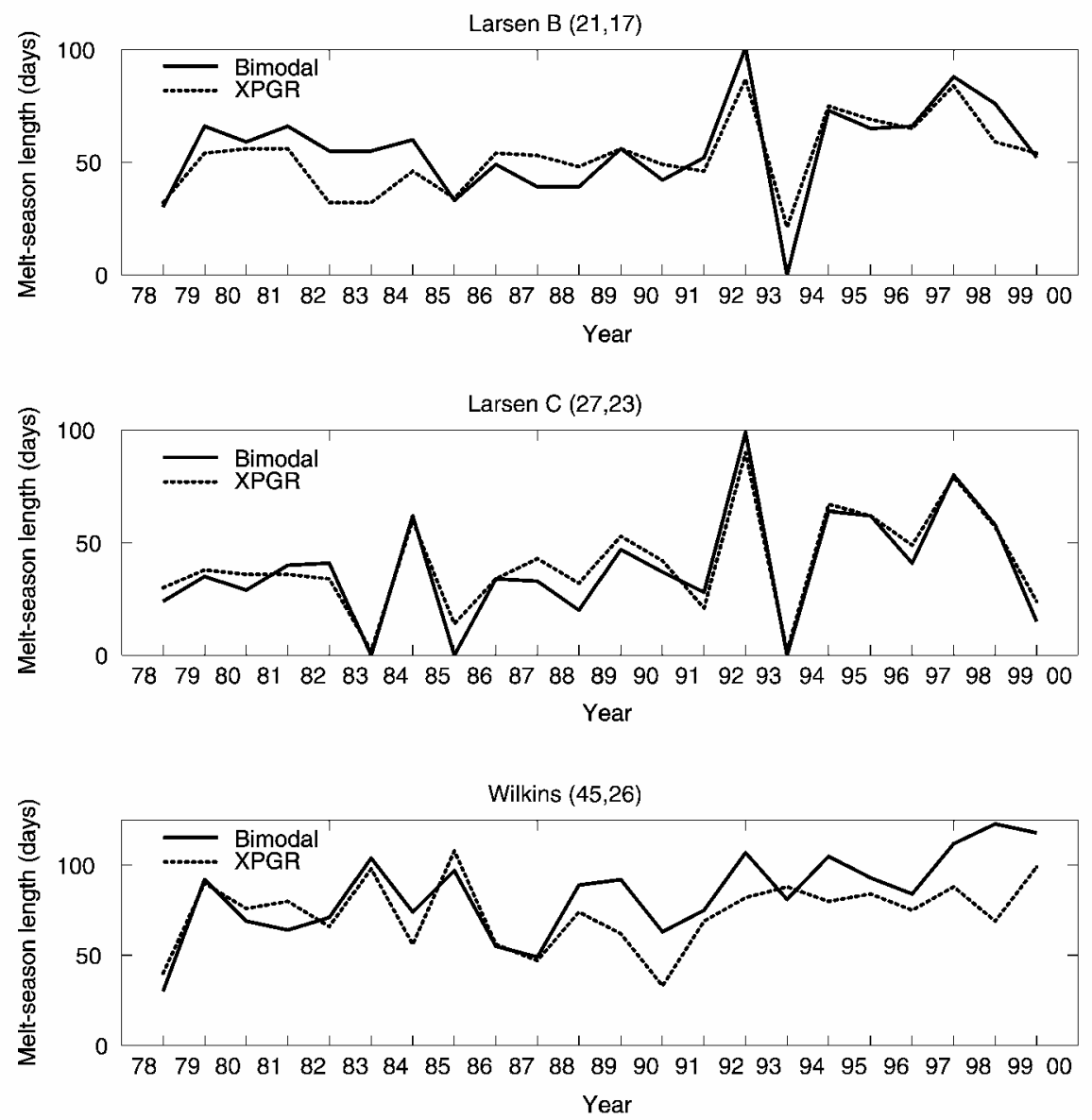

Fig. 5. Melt-season lengths for three pixels on two ice shelves, determined using both XPGR and the bimodal analysis discussed in the text. The lengths of each melt season are plotted on 31 December of the year, and connected with lines to make it easier to see yearto-year variations. 


\section{ACKNOWLEDGEMENTS}

The authors were supported by NASA Headquarters Polar program. We wish to thank T. Scambos and C. Hulbe for useful discussions about ice-shelf processes, and J.-G. Winther and J.O. Hagen for helpful reviews.

\section{REFERENGES}

Abdalati, W. and K. Steffen. 1995. Passive microwave-derived snow melt regions on the Greenland ice sheet. Geophys. Res. Lett., 22(7), 787-790.

Abdalati, W. and K. Steffen. 1997. Snowmelt on the Greenland ice sheet as derived from passive microwave satellite data. 7. Climate, 10(2), 165-175.

Abdalati, W. and K. Steffen. 1998. Accumulation and hoar effects on microwave emission on the Greenland ice-sheet dry-snow zones. F. Glaciol., 44(148), 523-531.

Doake, C. S. M., H. F. J. Corr, H. Rott, P. Skvarca and N. W. Young. 1998. Breakup and conditions for stability of the northern Larsen Ice Shelf, Antarctica. Nature, 391(6669), 778-780.

King, J. C. 1994. Recent climate variability in the vicinity of the Antarctic Peninsula. Int. F. Climatol., 14(4), 357-369.

Lucchitta, B. K. and C. E. Rosanova. 1998. Retreat of northern margins of George VI and Wilkins Ice Shelves, Antarctic Peninsula. Ann. Glaciol., 27, $41-46$.

Mote, T. L. and M. R. Anderson. 1995. Variations in snowpack melt on the Greenland ice sheet based on passive-microwave measurements. F. Glaciol., 41(137), 51-60.
Ridley, J. 1993. Surface melting on Antarctic Peninsula ice shelves detected by passive microwave sensors. Geophys. Res. Lett., 20(23), 2639-2642.

Rott, H., P. Skvarca and T. Nagler. 1996. Rapid collapse of northern Larsen Ice Shelf, Antarctica. Science, 271(5250), 788-792.

Rott, H., W. Rack, T. Nagler and P. Skvarca. 1998. Climatically induced retreat and collapse of northern Larsen Ice Shelf, Antarctic Peninsula. Ann. Glaciol., 27, 86-92.

Scambos, T. A., C. Hulbe, M. Fahnestock and J. Bohlander. 2000. The link between climate warming and break-up of ice shelves in the Antarctic Peninsula. F. Glaciol., 46(154), 516-530.

Shuman, C. A. and R. B. Alley. 1993. Spatial and temporal characterization of hoar formation in central Greenland using SSM/I brightness temperatures. Geophys. Res. Lett., 20(23), 2643-2646.

Skvarca, P., W. Rack, H. Rott and T. Ibarzábal y Donángelo. 1998. Evidence of recent climatic warming on the eastern Antarctic Peninsula. Ann. Glaciol., 27, 628-632.

Ulaby, F.T., R. K. Moore and A. K. Fung. 1981. Microwave remote sensing, active and passive. Vol. 1. Fundamentals and radiometry. Reading, MA, AddisonWesley Publishing Co.

Van derVeen, C. J. 1998. Letters. Melting, maybe. Science, 281(5381), 1285-1286.

Vaughan, D. G. 1993. Implications of the break-up of Wordie Ice Shelf, Antarctica for sea level. Antarct. Sci., 5 (4), 403-408.

Vaughan, D. G. and C. S. M. Doake. 1996. Recent atmospheric warming and retreat of ice shelves on the Antarctic Peninsula. Nature, 379(6563), 328-331.

Zwally, H. J. and S. Fiegles. 1994. Extent and duration of Antarctic surface melt. f. Glaciol., 40 (136), 463-476.

Zwally, H.J. and P. Gloersen. 1977. Passive microwave images of the polar regions and research applications. Polar Rec., 18(116), 431-450. 